\title{
Economic stress, emotional contagion and safety outcomes: A cross-country study
}

\author{
Laura Petitta $^{\mathrm{a}, *}$, Tahira M. Probst ${ }^{\mathrm{b}}$, Valerio Ghezzi ${ }^{\mathrm{a}}$ and Claudio Barbaranelli ${ }^{\mathrm{a}}$ \\ ${ }^{a}$ Sapienza University of Rome, Rome, Italy \\ ${ }^{\mathrm{b}}$ Washington State University Vancouver, Vancouver, WA, USA
}

Received 10 June 2019

Accepted 27 March 2020

\begin{abstract}
.
BACKGROUND: Economic instability produced by financial crises can increase employment-related (i.e., job insecurity) and income-related (i.e., financial stress) economic stress. While the detrimental impact of job insecurity on safety outcomes has been extensively investigated, no study has examined the concurrent role of financial stress let alone their emotion-related predictors.

OBJECTIVE: The present cross-country research sought to identify the simultaneous effects of affective job insecurity and financial stress in predicting employee safety injuries and accidents under-reporting, and to examine the extent to which emotional contagion of positive/negative emotions at work contribute to the level of experienced economic stress.

METHODS: We performed multi-group measurement and structural invariance analyses.

RESULTS: Data from employees in the U.S. $(\mathrm{N}=498)$ and Italy $(\mathrm{N}=366)$ suggest that financial stress is the primary mediator between emotional contagion and poor safety outcomes. Moreover, greater anger-contagion predicted higher levels of financial strain and job insecurity whereas greater joy-contagion predicted reduced economic stress.

CONCLUSIONS: Our findings support the relevance of considering the concurrent role of income-and employment-related stressors as predictors of safety-related outcomes. Theoretical and practical implications for safety are discussed in light of the globally increasing emotional pressure and concerns of income- and employment-related economic stress in today's workplace, particularly given the recent pandemic spread of Corona virus disease (COVID-19).
\end{abstract}

Keywords: Economic stress, emotional contagion, workplace injuries, accident under-reporting

\section{Introduction}

The economic crisis of 2008 produced world-wide economic instability, leading to increased longterm unemployment and, among those fortunate to keep their jobs, greater uncertainty about their future employment prospects [1]. Even prior to the recent global Corona virus (COVID-19) pandemic,

*Address for correspondence: Laura Petitta, Department of Psychology, Sapienza University of Rome, Via dei Marsi, 78, 00185, Rome, Italy. Tel.: +39 06 49917641; E-mail: laura.petitta@uniroma1.it. surveyed workers in the United Stated reported stress about money and place money and work as top economic concerns [2, 3]. Similarly, in Italy, unemployment stands at nearly $12 \%$ [4] with $6.9 \%$ long-term unemployed and many more engaged in precarious work. According to a recent Eurobarometer [5] survey, $73 \%$ of Italian employees rate their working conditions as poor (compared to $43 \%$ overall in the EU28) and 85\% report conditions have deteriorated over the past five years. The COVID19 pandemic is certain to only exacerbate economic conditions as evidenced by the staggering 3.3 million jobless claims filed in a single week within the 
U.S. with likely many more to occur in the weeks and months to come.

Given these existing working conditions, the purpose of the current study was to examine the relationship between economic stressors at work and their relationship with work-related safety outcomes in two samples, one from the US and the other from Italy. In doing so, we sought to enhance the conceptual replication $[6,7]$ of our hypotheses, and increase the generalizability of our findings. Moreover, because employees often share with other people at work their concerns, fears, as well as joys regarding their work situation, we also sought to examine how the sharing of such emotions (i.e., emotional contagion) might be predictive of reported levels of economic stress.

Economic stressors refer to objective and subjective aspects of income and employment that serve as potential stressors to individuals and their families [8]. Potential employment-related stressors include job insecurity (a subjective employment stressor regarding one's future employment), whereas income-related stressors include variables such as financial stress (a subjective income stressor related to financial concerns and worries) and objective loss of income [9]. Among these economic stressors, multiple research studies indicate that job insecurity predicts a decline in worker safety attitudes and behaviors (e.g., safety motivation and compliance) and an increase in adverse workplace safety outcomes, such as accident under-reporting and injuries [10-12]. This relationship was also demonstrated to be even more critical among temporary workers both in the U.S. and Italy [13].

Taken together, this study has three main aims, each contributing to the extant literature in a unique way. The first aim was to identify the conjoint role of job insecurity and financial stress toward predicting employee safety injuries and accidents under-reporting. Unfortunately, while the relationship between the economic stress of job insecurity and worker safety is becoming clearer, no research to date has examined whether income-related stress has a similar relationship. As a result, little is known about the relationship between other relevant and pervasive economic stressors (such as underemployment and financial stress) and workplace safety outcomes (e.g., accident under-reporting, injuries). Such an omission is critical, since employment- and income-related stressors often co-occur; therefore, failure to include both risks miss specifying their relative importance. Thus, our research responds to recent calls (e.g., [14,
15]) to better understand the contributions of financial stress in conjunction with other economic stressors, such as job insecurity.

The second aim was to provide an empirical examination of the affective dimensions of economic stress, as opposed to the cognitive ones, since they have been found to be stronger predictors of outcomes of economic stress than the cognitive dimensions [16, 17]. Specifically, research indicates that there is an important theoretical distinction between cognitive and affective facets of economic stress. For example, within the job insecurity literature, research indicates that cognitive and affective insecurity are two separate constructs [30]. In particular, cognitive job insecurity is defined as "perceived powerlessness to maintain desired continuity in a threatened job situation"([18] p. 438), and thus refers to a cognitive awareness of the possibility of job loss (although not necessarily any given level of distress at the prospect). Conversely, affective job insecurity is the emotional experience of being emotionally anxious about these potential losses [15]. Similarly, perceived financial inadequacy is the cognitive judgement of a lack of financial resources, whereas perceived financial stress represents the affective reaction to that inadequacy. In the current study we go beyond the well-established study of employment-related stressors (i.e., job insecurity) by adding the underexplored area of income-related stressors (i.e., financial stress).

The third aim was to examine whether and to what extent emotional contagion of positive/negative emotions at the workplace may play a role in increasing or decreasing experienced levels of economic stress (i.e., job insecurity, financial stress) and safety outcomes. Specifically, emotional contagion is the automatic and unintentional tendency of humans to absorb emotional cues of another individual, thus converging emotionally on the same affective experience [19]. As such, emotional contagion involves implicit processes through which the emotion is interpersonally induced [20], and a primary mechanism through which emotions are shared and become social [21].

Given the focus of the current study on the affective dimensions of economic stress (i.e., affective job insecurity, financial stress), we argue that they are most likely to be influenced by emotional contagion at work. Specifically, the current study goes beyond the study of affect-related factors that occur solely within the individual (e.g., anxiety) and focuses on emotional contagion as an emotion-related factor with a strong social component which can influence both 
the experience of stress at work (e.g., job burnout, [22]) and relevant safety outcomes (i.e., workplace injuries, accidents). Understanding emotional contagion as an antecedent of economic stress and safety outcomes is important because it would allow us to develop effective emotion management interventions including knowledge on how social interactions contribute to shape emotional life of employees and their subsequent feelings of economic stress and likelihood of experiencing accidents/injuries at work.

In the sections below, we review the literature and develop our hypotheses on the relationship between economic stress, emotional contagion and safety outcomes.

\subsection{Employment-related economic stress and safety outcomes}

Job insecurity is best described as a subjective phenomenon that is "in the eye of the beholder" (e.g. $[10,23]$ ), and can also be referred to the perceived likelihood of losing one's job [24]. As such, it refers to a potential subjective economic stressor related to individual's employment status [9]. Numerous studies have demonstrated that employees with insecure jobs increase risk taking behaviors at work [25], and suffer more injuries and accidents compared to employees with relatively more secure jobs (i.e., $[26,27])$. This relationship has also been replicated across different national contexts and labor markets. More specifically, research [12] has established that when employees feel their job to be more insecure they not only experience more accidents at work, but also tend to not report those accidents to appropriate company officials. Hence, higher levels of job insecurity are related to greater accident underreporting (i.e., discrepancies between the number of accidents experienced and the number reported).

A relevant contribution in understanding the link between job insecurity and safety outcomes was Borg and Elizur's [28] distinction between the affective versus cognitive nature of job insecurity. As noted above, employees' beliefs about perceived threats to future stability of their job reflects the cognitive component of job insecurity whereas the emotional state and reaction to the subjective anticipation of such an involuntary event reflects the affective component [29]. As such, affective job insecurity refers to concerns and worries regarding potential job loss.

Research has shown that not only there is a difference between cognitive and affective job insecurity [30], but that is the affective component that tend to be more proximally related to poor safety outcomes of our interest [16, 17]. Despite this well-established conceptual difference, a large number of studies continue to either overlook affective job insecurity or conflate the two in their operationalization [31]. Moreover, while the relevance of differentiating between cognitive vs. affective job insecurity has been widely acknowledged, research on the impact of affective job insecurity on workplace injuries and accident under-reporting is still scarce. Recently, Jiang and Probst [32] found that affective job insecurity predicted higher rates of workplace accidents among 639 employees from six different companies. Consistent with the above arguments, we expect to find the following:

Hypothesis 1: Affective job insecurity positively predicts the levels of workplace injuries (1a) and accident under-reporting (1b).

\subsection{Income-related economic stress and safety outcomes

Similar to the cognitive vs. affective components of job insecurity, financial stress refers to the distressed emotional reaction associated with individuals' perceived likelihood of the occurrence of unwanted and threatening events related to income loss and financial difficulties. While research on job insecurity has a long tradition, studies on financial stress, and particularly on the link with workplace safety, are still nascent. Moreover, as is the case within much of the job insecurity literature, extant measures of financial stress (e.g., [33, 34]) still tend to contain both cognitive (i.e., beliefs, judgements) and affective (i.e., feelings, concerns) items. Such operational conflation of the two aspects also makes it difficult to tease out their effects and differential predictors. Therefore, for the purpose of the current study, we developed a measure of affective financial stress which captures emotional and attitudinal reactions to potential financial inadequacy.

Present research on income and economic deprivation has shown links with poorer health and psychological well-being. For example, the financesshame model [35] suggests that financial hardship combined with the shame associated with financial hardship leads to adverse health outcomes. Despite some evidence of the impact of economic deprivation on job attitudes and performance [36], there is still scant financial research specifically on occupational health [14], let alone on how economic stress (e.g., perceived financial stress) apply to organizational 
contexts and safety-related outcomes in particular. However, based on the above arguments, we have reason to expect the following:

Hypothesis 2: Financial stress positively predicts the levels of workplace injuries (2a) and accident under-reporting $(2 b)$.

\subsection{Emotional contagion at work, economic stress, and safety outcomes}

Affective economic stress represents an adverse emotional reaction to environmental pressures related to employment and income sources of uncertainty. According to Clark, Knabe, and Rätzel [37], poor economic conditions increase the prevalence of unemployment within communities, thereby increasing individuals' perceptions of the likelihood that they will lose their job. In other words, economic stress is contagious. Indeed, research indicates that individual perceptions of job insecurity are "contagious" and can create a workplace climate of job insecurity [38].

Emotional contagion (EC; [39]) is the nonconscious process through which humans automatically detect emotions of those with whom they relate, thus allowing absorption of the same emotion [40]. People tend to mimic the facial, vocal, postural, and behavioral emotional cues "of those around them, and thereby "catch" others' emotions as a consequence of such facial, vocal, and postural feedback" ([39] p.3). Thus, it refers to an individual experience of emotion that includes the interpersonal component of the feelings exchanged during social encounters [39]. The simultaneous detection and reflection of the emotional cues of others occurs below conscious recognition and is enabled by the Mirror Neuron System mimicking the brain activation pattern underlying an emotional stimulus [41, 42]. Although emotional contagion is activated involuntarily and automatically, the neocortex receives the emotional signal milliseconds thereafter thus enabling the conscious awareness of one's emotional exchanges with others[43]. As such, emotional contagion involves "epidemic" spreading of emotions in large social communities [44] and among all people interacting at work [45].

While emotional contagion has an inherent social component, it can be studied [21], and consistently operationalized, at the individual (e.g., being prone to catching other people's emotions, [19], dyadic (e.g., emotional exchanges between: salespersons and customers; teachers and students, [46]), and group level (e.g., affect transfer among group members,). The present paper engages an individual-level perspective of emotional contagion, understood as the individual's experience of feeling an emotion that s/he has absorbed from other people while interacting in the workplace. Furthermore, it focuses on the absorption of specific basic emotions, as proposed by Doherty [47], rather than measuring an individual general susceptibility to pick a mix of others' affective clues, such as emotions, feelings, moods [40]. We purposefully focus on the contagion of basic, discrete emotions because basic emotions are universal features of all humans [48], thus increasing the likelihood of generalizability of the research findings and applications. Finally, in the current study we conceptualize emotional contagion at work as emotional exchanges contextualized to work settings, rather than in various situations of an individual's life [47, 40].

Indeed, emotional contagion is a predictor of stress associated with work [22]. More specifically, consistent with the Job Demands-Resource (JD-R) model of work-related stress [49], a study from Petitta, Jiang and Hartel [50] in healthcare settings found that contagion of anger may serve as a job demand that is related to increased job burnout (i.e., job stress) whereas contagion of joy may serve as a job resource that is related to reduced burnout.

While a job resource is an objective or subjective aspect of the job that stimulates and energizes the individual in achieving one's goal, a job demand is an objective or subjective aspects that requires sustained physical and/or psychological effort [51]. Moreover, both job demands and job resources have cognitive, emotional, and physical components $[52,53]$. The current study focuses on the emotional domain of job demands, which refer to emotionally taxing work requests, and the emotional aspect of job resources, which reduce the emotional pressure associated with work. As such, contagion of positive emotions (e.g., joy) may serve as a job resource by synchronizing opportunities, social bonding, and cooperation [54]. Conversely, contagion of negative emotions (e.g., anger) may have detrimental consequences and thus qualifies as a job demand by depleting psychological resources [55]. Consistently, we have reason to expect that contagion of joy and anger among people in organizations contribute to the cross-over of work-related economic stress (i.e., financial stress and affective job insecurity).

Using the JD-R model of work-related stress and emotional contagion literature as a theoretical foun- 
dation, we test the proposition that higher contagion of anger (i.e., a demand) will be associated with greater levels of subsequent affective job insecurity and financial stress, while higher contagion of joy (i.e., a resource) will be associated with lower levels of affective job insecurity and financial stress. Furthermore, literature [56] suggests that negative emotions (i.e., anger, frustration, anxiety) narrow employees' attention and subsequent carrying out of work in a safe manner, thus increasing the number of accidents they experience. For example, Dunbar [57] found that anxiety was related to reductions in employee use of personal protective equipment. Similarly, negative emotions may narrow perceptual focus thus causing individuals to miss important performance-related cues and act without considering the consequences of their actions [58]. Indeed, literature suggests that work-related stress is a significant safety concern [59]. In the current study, we expect a similar effect such that the contagion of anger (i.e., a demand) will interfere with employees energies and lead them to experience more workplace injuries as well as refrain from reporting to appropriate safety officers the accidents they experience (i.e., accident underreporting). Accordingly, we argue that contagion of joy (i.e., a resource) will energize employees and help them to experience less workplace injuries as well as encourage them to report the accidents they experience.

As a result, we have reason to expect that:

Hypotheses 3 \& 4: Emotional contagion of joy absorbed from others directly and negatively predicts affective job insecurity (3a) and financial stress (3b), whereas emotional contagion of anger absorbed from others directly and positively predicts affective job insecurity (4a) and financial stress (4b).

Hypotheses 5 \& 6: Emotional contagion of joy absorbed from others negatively predicts (5a) workplace injuries and (5b) accident under-reporting, both directly and indirectly via affective job insecurity and financial stress. Emotional contagion of anger absorbed from others positively affects (6a) workplace injuries and (6b) accident under-reporting, both directly and indirectly via affective job insecurity and financial stress.

Literature suggests that workplace aggression is likely to thrive in environments where job insecurity is high due to co-workers being seen as potential rivals and leaders not emphasizing civility as a priority during turbulent times [60]. Indeed, previous research [50] found that interpersonal interactions at work might play an influential role in respondents' levels of joy and anger absorbed. In line with emotional contagion theory's claim that the absorption of an emotion is grounded in social exchanges, we have reason to predict that social interactions with different stakeholders at work (e.g., leaders, colleagues) will contribute to produce different absorption levels of joy or anger. Specifically, anger and joy absorbed from leaders and from colleagues predict the level of contagion of anger and joy respectively, and, in turn, levels of work-related stress (i.e., burnout). Building on these premises, we expect that:

Hypotheses 7\& 8: Joy associated respectively with leaders (7a), and colleagues (7b), directly and positively predicts the levels of joy absorbed. Anger associated respectively with leaders (8a), and colleagues (8b), directly and positively predicts the levels of anger absorbed.

Hypotheses 9 \& 10: Joy associated respectively with leaders (9a) and colleagues (9b), indirectly and negatively predict workplace injuries and accident under-reporting via emotional contagion of joy, affective job insecurity and financial stress. Anger associated respectively with leaders (10a) and colleagues (10b) indirectly and positively predict workplace injuries and accident under-reporting via emotional contagion of anger, affective job insecurity and financial stress.

\section{Method}

\subsection{Participants and procedure}

In order to test our hypotheses, data were gathered from employees within the US and Italy.

US Sample. Online anonymous surveys were administered to 498 participants in the United States. The demographics of the sample description are reported in Table 1.

After providing participants with informed consent materials that explained the anonymous nature of the data collection and their rights as research participants, employees completed the on-line survey containing the research measures through Amazon Mechanical Turk, an online crowd sourcing website.

Italian Sample. Paper and pencil surveys were administered in person to 366 participants in Italy. The demographics of the sample description are reported in Table 1.

Members of the research team provided participants with informed consent materials that explained the anonymous nature of the data collection and their 
Table 1

Demographics of the US and Italian samples

\begin{tabular}{|c|c|c|c|c|c|}
\hline Variable & & $\%$ & Range & Mean & SD \\
\hline \multicolumn{6}{|l|}{ US sample $(N=498)$} \\
\hline \multirow{2}{*}{ 1. Gender } & Male & $55 \%$ & & & \\
\hline & Female & $44 \%$ & & & \\
\hline \multirow[t]{2}{*}{ 2. Contract } & Permanent & $84 \%$ & & & \\
\hline & Contingent & $16 \%$ & & & \\
\hline 3. Age & & & & $35.1 \mathrm{yrs}$. & 10.5 \\
\hline 4. Organizational tenure & & & & 5.4 yrs. & \\
\hline 5. Total Household Income & & & & $62.049,91 \$$ & $37.622,76$ \\
\hline 6. Household members & & & $1-8$ persons & 2.67 persons & 1.4 \\
\hline \multicolumn{6}{|l|}{ Italian sample $(N=366)$} \\
\hline \multirow[t]{2}{*}{ 1. Gender } & Male & $45.6 \%$ & & & \\
\hline & Female & $54.5 \%$ & & & \\
\hline \multirow[t]{2}{*}{ 2. Contract } & Permanent & $15 \%$ & & & \\
\hline & Contingent & $85 \%$ & & & \\
\hline 3. Age & & & & $31.9 \mathrm{yrs}$. & 11.3 \\
\hline 4. Organizational tenure & & & & $5.3 \mathrm{yrs}$ & 6.8 \\
\hline 5. Total Household Income & & & & $24.224,20 €$ & $18.311,71 €$ \\
\hline 6. Household members & & & $1-7$ persons & 3 persons & 1.2 \\
\hline
\end{tabular}

rights as research participants, and distributed the questionnaire. Employees were allowed to complete the survey at home and return it in a sealed envelope, in order to assure confidentiality, to the research team.

\subsection{Measures}

The US and Italian versions of the survey contained the following scales, respectively worded in English and Italian:

Accidents Under-reporting. Using a measure from Probst, Graso, Estrada, and Greer, [61], employees were asked to indicate how many safety accidents they reported to appropriate company officials and how many accidents they had experienced but not reported to their supervisor over the past 12 months. Using these data, we could compute the total number of experienced accidents for comparison to the number actually reported. Although the workplace accident variables are self-report in nature, previous studies do indicate that self-report measures of accidents and unsafe behaviors are related to independent observations of these variables [62].

Workplace Injuries. We used a15-item self-report measure of workplace injuries [61] experienced during past year (e.g., back injury, cut/puncture wound, broken bone, eye irritation). Workplace injuries were assessed by totalling the number of injuries workers indicated they had experienced as a result of their job, and could range from 0 to 12 .

Affective job insecurity. Six items from Probst's [17] measure of affective job insecurity (the Job Security Satisfaction scale) were used to assess the respondent's feelings and evaluative assessment about his or her job security. Respondents indicated on a 3-point scale (yes, don't know, no) the extent to which each adjective or phrase described the stability of their job. A sample items is "upsetting how little job security I have." Using a scoring system recommended by Hanisch [63], item responses were coded as follows: agreement with negatively worded items (i.e., "nerve-wracking") was scored 3; agreement with positively worded items (i.e., "looks optimistic") was scored 0; and "don't know" responses were scored 2. Hence, higher scores reflected greater affective job insecurity.

Affective Financial stress. We used four Likert scale items developed by the second author of the present paper to assess the affective nature of financial stress based on a prior Delphi study [64] that identified common themes associated with financial stress.Respondents indicated on a 5-point frequency scale ranging from 1 (Never) to 5 (Always) how often they experienced concerns and worries related to stressful economic situations. Items included: "I worry about having the funds to cover normal monthly expenses"; "I feel like I am living paycheck-to-paycheck"; "I am stressed by my financial situation"; and "An unexpected event such as a car repair could cause a financial emergency for me."

Emotional Contagion. Emotional contagion from the perspective of basic and discrete emotions absorbed by the respondent (i.e., EC absorbed) at the workplace was measured by the Emotional Contagion at Work Scale (ECWS; [45]). Previous findings support the empirical distinctiveness of con- 
tagion of the two discrete basic emotions assessed in this research, namely, joy and anger [45]. The ECWS assesses emotional contagion by presenting respondents with items that represent different work-situated emotional experiences. For example, a sample item from the 4-item joy-absorbed subscale is, "Interacting with happy people makes me feel better when I am a little down", and a sample item from the 4-item anger-absorbed subscale is, "When someone is angry and raises their voice, I become irritated." For each item participants receive two separate prompts. The first prompt asks participants to answer how frequently the emotional situation is experienced using a 5-point Likert scale ranging from 1 (Never) to 5 (Always). The second prompt asks participants to indicate with whom the described emotional situation happens by selecting the applicable stakeholders: leaders and colleagues. For this latter scale, responses were coded " 0 "/ " 1 " depending on whether the emotional experience was respectively NOT associated/associated with the stakeholder.

The scale format allowed us to compute two different scores. First, we computed the overall scores of joy-absorbed and anger-absorbed by averaging the selected frequency of the joy-related and angerrelated items respectively. Higher scores of "joy absorbed" and "anger absorbed" reflect greater levels of joy and anger being absorbed from others at work. The second response scale allowed us to compute the average scores on the following four dimensions: 1) joy-absorbed from leaders; 2) joy-absorbed from colleagues; 3) anger-absorbed from leaders; and 4) anger-absorbed from colleagues. For example, we computed the overall scores of joy-absorbed from leaders by averaging the answers ( $0 / 1$ response) to the four items of joy-absorbed-leaders.

\section{Statistical procedures}

We first assessed the measurement invarianceof the English and Italian version of the study scales. All models were carried out with M plus 8 [65] using the weighted least squares-mean and variance adjusted (WLSMV) estimation given the ordered categorical nature of our items which are evaluated by Likert-type answer formats [66]. We first performed separate confirmatory factor analyses (CFA) for the US and Italian samples, and evaluated the indices of goodness of fit to the data [67]. Second, we used the multiplegroup confirmatory factor analysis (MGCFA) to test and compare progressively more constrained models in order to assess the following measurement invariance: configural (equality for form with no invariance constraints on parameters), metric (equality for factor loadings), scalar (equality for items' thresholds), and strict (residual variances). Using the procedure proposed by Cheung and Rensvold [68], one can conclude that the additional constraints are appropriate and can be maintained if the model's chi-square does not change significantly and the decrease in Comparative Fit Index (CFI) between adjacent nested models is less than 0.01. When there is some support for measurement invariance, structural invariance can be examined. In accordance with Kline [67], we followed three steps. First, we examined separately the relative fit of a structural regression model for the U.S. and Italian samples. Second, we performed a single analysis across both groups without any constraints and by taking into account the highest level of measurement invariance reached in measurement invariance. Third, we tested the equality of structural path coefficients across groups by comparing this model with the former. Finally, we bootstrapped 10,000 times estimates from the final structural model [69] in order to assess the magnitude and the significance of the specific indirect effects, by interpreting their standardized estimates along with the associated 95\% confidence intervals.

\section{Results}

\subsection{Descriptive statistics and correlations}

The means, standard deviations, reliability estimates, and zero-order correlations among the study variables were calculated separately for the US and Italy sub-samples. As shown in the diagonal of Table 2, each study variable meets the criterion for internal consistency reliability, ranging from 0.82 to 0.93 in the U.S. and 0.77 and 0.93 in Italy. While the pattern of correlations was similar across the two countries, Italian workers exhibited significantly higher means than US workers on financial stress, affective job insecurity and emotional contagion of anger, and a significantly lower mean on workplace injuries; differences were examined with Student's t for independent samples and they were all significant at $p<0.001$. The means of accident under-reporting and emotional contagion of joy were not statistically different. We will consider these differences further in the results section in light of the measurement invariance results. 


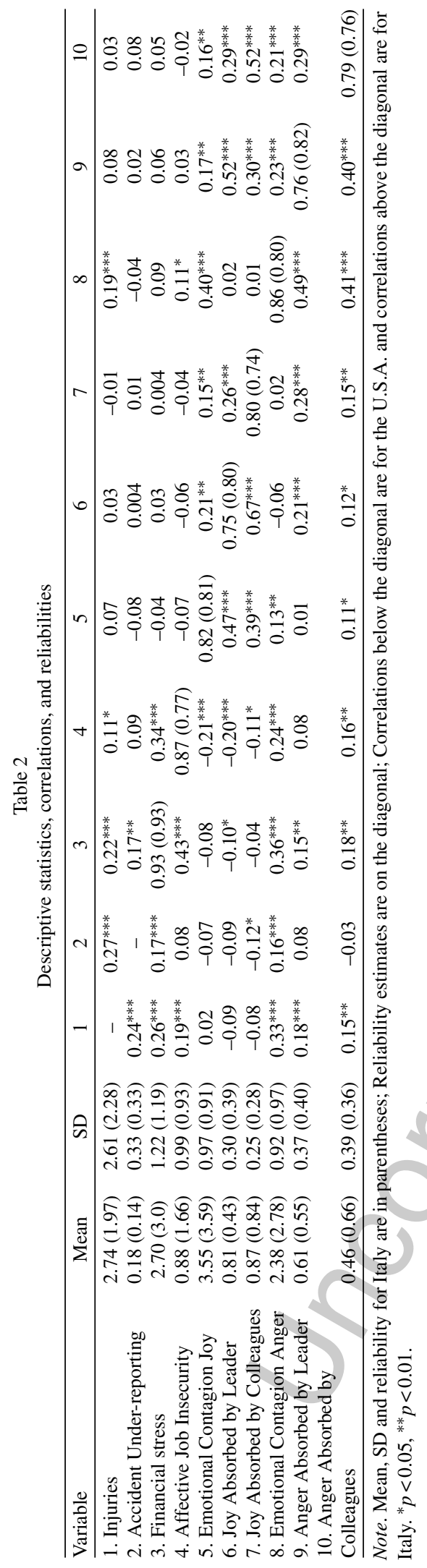

\subsection{Goodness of fit for the measurement models of the single groups}

613

614

Prior to conducting multiple-group analyses for testing our hypotheses, we examined the goodnessof-fit values of the four-factor CFA models separately for the US and Italy samples. The values for the US sample (see Table 3) were $\chi^{2}$ (129, $\mathrm{N}=498)=224.710$, RMSEA $=0.039(0.030-0.047)$, $\mathrm{CFI}=0.98$, TLI $=0.98$, showing an excellent fit. Each indicator had statistically significant $(p<0.001)$ factor loadings on its assigned construct, with all standardized values greater than 0.69. Similarly, the fit indices for the Italian sample were $\chi^{2}(129$, $\mathrm{N}=357)=200.146$, RMSEA $=0.039(0.028-0.050)$, $\mathrm{CFI}=0.94, \mathrm{TLI}=0.93$, thus indicating an excellent fit. Further, each indicator had statistically significant $(p<0.001)$ factor loadings on its assigned construct, with all standardized values greater than 0.63 .

Correlations among emotional contagion (i.e., joy, anger) and economic stress (i.e., financial stress, affective job insecurity) factors ranged from -0.10 to 0.41 in the US and from -0.05 to 0.48 in Italy. On the other hand, correlations between financial stress and affective job insecurity was 0.49 in the US and 0.41 in Italy. These results demonstrated the appropriateness of the four hypothesized latent factors and the distinctiveness of emotional contagion factors (i.e., joy and anger), financial stress, and affective job insecurity.

\subsection{Multiple group CFA analyses for measurement invariance across the US and Italy}

Table 3 shows the results of analyses for measurement invariance testing across the Us and Italy. We used the DELTA parameterization (see [65]). Since unique variances are not locally identified in the configural model, they were fixed to unity in both groups (i.e., US, Italy) for each measurement invariance model (i.e., M1, M2, M3, M4). When constraints on factor loadings were added to test for metric invariance, the model (M2) still showed an excellent fit, and the $\Delta$ CFI was less than 0.01 in comparison to the configural model (M1). When constraints on thresholds were introduced to test for scalar invariance, the model (M3) still showed an excellent fit but did not satisfy the full scalar condition. Thus, after realising four thresholds pertaining to one item of emotional contagion of anger, partial scalar invariance (M4) was reached. Hence, there was an overall good evidence
645

646

647

648

649

650

651

652

653

654

655

656

657

658

659

660

661 
Table 3

Results of tests for measurement and structural invariance across U.S. and Italy

\begin{tabular}{|c|c|c|c|c|c|c|c|}
\hline \multirow[b]{2}{*}{$\operatorname{Models}(\mathrm{M})$} & \multicolumn{5}{|c|}{$\begin{array}{l}\text { Model } \\
\text { Fit }\end{array}$} & \multicolumn{2}{|c|}{$\begin{array}{c}\text { Model } \\
\text { Difference }\end{array}$} \\
\hline & $\chi^{2}$ & $d f$ & $\begin{array}{l}\text { RMSEA (90\% } \\
\text { CI) }\end{array}$ & CFI & $\overline{\text { TLI }}$ & $\Delta \mathrm{M}$ & $\overline{\Delta \mathrm{CFI}}$ \\
\hline Model U.S. & 479.051 & 201 & $\begin{array}{l}0.053 \\
(0.047-0.059)\end{array}$ & 0.981 & 0.978 & - & - \\
\hline Model Italy $_{\text {}}$ & 373.417 & 201 & $\begin{array}{l}0.048 \\
(0.041-0.056)\end{array}$ & 0.982 & 0.979 & & - \\
\hline M1: Configural & 853.887 & 402 & $\begin{array}{l}0.051 \\
(0.046-0.056)\end{array}$ & 0.981 & 0.979 & & - \\
\hline M2: Metric & 936.372 & 416 & $\begin{array}{l}0.054 \\
(0.049-0.058)\end{array}$ & 0.979 & 0.976 & M1-M2 & 0.002 \\
\hline M3: Scalar & 1273.711 & 472 & $\begin{array}{l}0.063 \\
(0.059-0.067)\end{array}$ & 0.967 & 0.968 & M2-M3 & 0.012 \\
\hline M4: Partial Scalar & 1187.585 & 468 & $\begin{array}{l}0.060 \\
(0.055-0.054)\end{array}$ & 0.970 & 0.971 & M2-M4 & 0.009 \\
\hline S5: Structural Model for U.S. & 380.228 & 233 & $\begin{array}{l}0.036 \\
(0.029-0.042)\end{array}$ & 0.975 & 0.971 & - & - \\
\hline S6: Structural Model for Italy & 306.969 & 233 & $\begin{array}{l}0.030 \\
(0.020-0.039)\end{array}$ & 0.946 & 0.936 & - & - \\
\hline S7: Unconstrained Structural Model across groups & 1208.535 & 540 & $\begin{array}{l}0.054 \\
(0.050-0.058)\end{array}$ & 0.972 & 0.972 & - & - \\
\hline S8: Constrained Structural Model across groups & 1212.223 & 556 & $\begin{array}{l}0.053 \\
(0.049-0.057)\end{array}$ & 0.973 & 0.973 & S7-S8 & -0.001 \\
\hline
\end{tabular}

Note. At each step in the sequence of invariance tests, all earlier constraints remain in place (excepting for M4, where we released four constraints with respect to M3). RMSEA = Root Mean-Square Error of Approximation; CFI = Comparative Fit Index; TLI=Tucker-Lewis Index.

of no substantial item bias in the data, indicating that scale means of the contagion of joy, contagion of anger, financial stress, and job insecurity measures can be meaningfully compared across countries also at the observed level.

\subsection{Multi group structural equation models}

In the first step, we examined separately the goodness-of-fit values for the structural equation models for the US and Italy. As shown in Table 3, the values for both the US (S5) $\left[\chi^{2}(\mathrm{df}=233)=\right.$ 380.228, RMSEA $=0.036(0.029-0.042), \mathrm{CFI}=0.98$, $\mathrm{TLI}=0.97]$ and Italy $(\mathrm{S} 6)\left[\chi^{2}(\mathrm{df}=233)=306.969\right.$, RMSEA $=0.030(0.020-0.039), \mathrm{CFI}=0.95, \mathrm{TLI}=$ 0.94] model showed good fit to the data.

Results from the subsequent comparison of single analysis across both US and Italy without any constraints (model S7 in Table 3) and with constrained imposed (S8) showed that here was not a significant decrement in model fit, thus supporting an invariant pattern of relationships among variables across the US and Italy. The final best fitting model is presented in Fig. 1.

As can be seen, financial stress exerted a positive effect on workplace injuries (respectively, 0.14, $p<0.01$, for the US, and $0.17, p<0.01$, for Italy) and on accident under-reporting $(0.25, p<0.01$ for the US and $0.09, p<0.01$ for Italy). However, affective job insecurity did not exert a significant effect on workplace injuries or on accident under-reporting (both for the US and Italy). Thus, across both the US and Italy, Hypotheses $2 \mathrm{a}$ and $2 \mathrm{~b}$ on the effect of financial stress on safety outcomes (i.e., workplace injuries and accident under-reporting) were supported whereas Hypotheses $1 \mathrm{a}$ and $1 \mathrm{~b}$ on the effect of affective job insecurity on safety outcomes were not. Moreover, financial stress showed a positive correlation with affective job insecurity $(0.43, p<0.01$ for the US and $0.36, p<0.01$ for Italy), while workplace injuries showed a positive correlation with accident underreporting $(0.18, p<0.01$ for the US and $0.17, p<0.01$ for Italy).

Emotional contagion of joy exerted a negative effect on financial stress $(-0.19, p<0.01$ for the US and $-0.17, p<0.01$ for Italy) and on affective job insecurity $(-0.26, p<0.01$ for the US and $-0.40, p<0.01$ for Italy). Further, contagion of joy did not exert a significant effect on workplace injuries or on accident under-reporting. Thus, only Hypotheses $3 \mathrm{a}$ and $3 \mathrm{~b}$ referring to the effect of contagion of joy on economic stress were supported, whereas Hypotheses $5 \mathrm{a}$ and $5 \mathrm{~b}$ referring to contagion of joy and safety outcomes were not. 


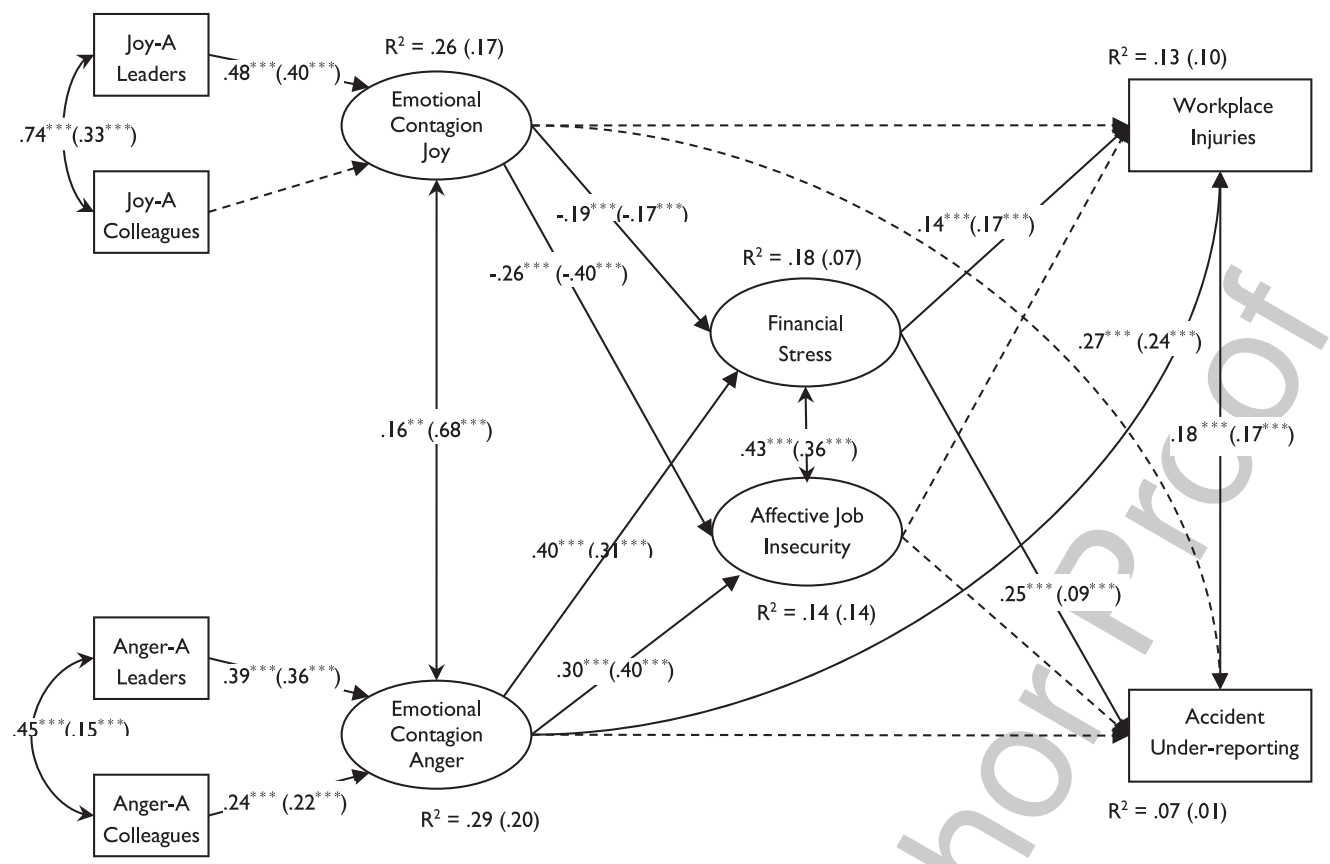

Note. ${ }^{* * *} p<.001,{ }^{* *} p<.01$; dotted lines are statistically non-significant estimates.

Fig. 1. Standardized structural coefficients for the final structural model for the U.S.A. and Italy (in parentheses). Note. ${ }^{* * *} p<0.001$, ${ }^{* *} p<0.01$; dotted lines are statistically non-significant estimates.

Emotional contagion of anger exerted a positive effect on financial stress $(0.40, p<0.01$ for the US and $0.31, p<0.01$ for Italy) and on affective job insecurity $(0.30, p<0.01$ for the US and $0.40, p<0.01$ for Italy). Further, contagion of anger exerted a significant positive effect on workplace injuries $(0.27, p<0.01$ for the US and $0.24, p<0.01$ for Italy) whereas did not exert any significant effect on accident under-reporting (both for the US and Italy). Thus, Hypotheses $4 \mathrm{a}$ and $4 \mathrm{~b}$ on the effect of contagion of anger on economic stress were supported. Further, Hypothesis 6a on the effect of contagion of anger on workplace injuries was supported whereas Hypothesis 6b referring to accident under-reporting was not.

Further, joy absorbed from leaders, but not from colleagues, positively predicted emotional contagion of joy $(0.48, p<0.01$ for the US and $0.40, p<0.01$ for Italy). Anger absorbed from leaders positively predicted emotional contagion of anger $(0.39, p<0.01$ for the US and $0.36, p<0.01$ for Italy). Similarly, anger absorbed from colleagues positively predicted emotional contagion of anger $(0.23, p<0.01$ for the US and $0.22, p<0.01$ for Italy). These findings provide near complete support for Hypotheses 9 and 10, with the exception of Hypothesis $9 \mathrm{~b}$ referring to anger absorbed from colleagues.
Finally, when considering the bootstrapped specific indirect effects for the US model, emotional contagion of joy exerted a negative effect only on accident under-reporting $(-0.02,-0.045--0.001)$ via financial stress. Emotional contagion of anger exerted a positive effect on both workplace injuries $(0.06$, $013-0.111)$ and accident under-reporting $(0.06,0.010$ $-0.117)$ via financial stress. When considering the indirect effects of emotional contagion sources, anger absorbed by colleagues exerted a positive effect $(0.02$, $0.001-0.036)$ on accident under-reporting via contagion of anger and financial stress. Further, anger absorbed by colleagues exerted a positive effect on workplace injuries via contagion of anger $(0.08$, $0.039-0.127)$ and via contagion of anger and financial stain $(0.02,0.002-0.034)$. The indirect effects of anger absorbed from leaders on accident underreporting via contagion of anger and financial stress was significant and positive $(0.03,0.006-0.043)$. Further, anger absorbed by leaders exerted a positive effect on workplace injuries via contagion of anger $(0.11,0.063-0.161)$. and via contagion of anger and financial stain $(0.02,0.004-0.044)$ Finally, for the Italian model, emotional contagion of anger exerted a specific indirect positive effect on workplace injuries $(0.04,0.003-0.078)$ and accident under-reporting 
$(0.07,0.001-0.136)$ via financial stress. Overall, the model explained the $13 \%$ of workplace injuries variance in the US and $10 \%$ in Italy, and $7 \%$ of accident under-reporting variance in the US and $1 \%$ in Italy.

\section{Discussion}

Workers in the United States annually experience nearly 3 million work-related injuries and illnesses [70], with over half being serious enough to require time away from work. In Italy, 468,698work-related injuries occur according to INAIL (Italian National Workers Compensation Authority; [71]). Despite the growing body of evidence on job insecurity predicting poor safety outcomes (e.g., injuries, accidents under-reporting), no research to date has examined whether these effects might differ when simultaneously examining other economic stressors, such as financial stress. The current cross-country (i.e., Italy, US) study fills this gap by investigating the differential role of employment- and income related stressors (i.e., financial stress, affective job insecurity) in predicting employee injuries and accident under-reporting. Furthermore, the study explores the concomitant effects of workplace contagion of both positive and negative emotions (i.e., joy, anger) on the perceived levels of economic stressors as well as the occurrence of poor safety outcomes.

Our findings suggest that financial stress is the primary mediator between emotional contagion and poor safety outcomes, thus highlighting the importance of considering not only employmentrelated stressors (e.g., affective job insecurity) but also income-related stressors (e.g., financial stress). Specifically, when taking into account both types of economic stressors, our results suggest that financial stress may be the more operative stressors explaining both safety outcomes. Hence, when employees are worried about the adequacy of their income, they not only experienced more injuries at work, but also tended to not report the accidents they experienced to appropriate company officials. Notably, these results are consistent (i.e., invariant) across different cultural contexts and also across different samples composition in terms of employment status (i.e., a majority of permanent workers in the US sample as opposed to a majority of contingent workers in the Italian one). Furthermore, results showed that the levels of both financial stress and affective job insecurity were increased by the contagion of anger whereas contagion of joy contributed to reduce the perception of economic stressors. This appears to be particularly relevant during the current pandemic spread of Corona virus disease (COVID-19) which renders safety of workers a major concern under the effects of such economic stressors and the emotional pressure shared among people (i.e., emotional contagion is intertwined with the medical contagion in the spreading of the disease). Additionally, as evidenced by the recent spikes in unemployment claims, financial and job insecurity will be of increasing concern to the point of affecting the medical crisis management strategies engaged by the many nations progressively involved in the pandemic.

Finally, our findings on the role of different social sources of contagion at work (i.e., leaders, colleagues) suggest that particularly relationships with leaders are the most relevant social paths in enhancing circulation of both joy and anger, thus stressing the relevance of leaders as a key role in our conceptual model of economic stressors and safety outcomes.

\subsection{Theoretical implications}

Together, our cross-country findings on how contagion of positive vs. negative emotions at work shape employee perception of economic stressors and subsequent poor safety outcomes make several novel contributions to the extant literatures in different areas - economic stress, safety, and emotional contagion. Most notably, we add knowledge to the economic stress and safety outcomes literatures by incorporating the study of financial stress as an additional economic stressor predicting injuries and accident reporting behavior. While affective job insecurity has already been shown to shape levels of injuries and accident under-reporting [31], our research indicates that consistently across two different cultures and normative national systems, employees income-related worries (i.e., financial stress) overshadow their affective reaction to employment-related concerns (i.e., affective job insecurity) in determining the injuries they experience and the number of accidents they decide to report. As such, employee concerns about their income may take precedence over their worries regarding job instability in prompting higher injuries and accident under-reporting, whether Americans or Italians, and whether permanent or contingent. These findings are consistent with American and European reports on the priority of concerns in people's life [2, 3], wherein financial inadequacy issues stand in top positions, and thus contribute to a better understand- 
ing of the dynamic interplay of different economic stressors in affecting employee safety outcomes. This would lend support to Warr's [72] Vitamin Model, suggesting that availability of money is among the nine posited environmental "vitamins" (i.e., needs) that people require in order to maintain their psychological health, and, by extension, to prevent from getting injured.

Our study also extends previous theorizing about emotional contagion by incorporating economic stress and safety. While literature has established the role of emotional contagion in shaping work-related stress (e.g., job burnout; [22]), this is the first study to consider how social exchanges of positive/negative emotions (i.e., contagion) at work may be related to employees levels of economic-related stress as well as accidents reporting behaviors and the likelihood of experiencing injuries. In particular, our findings contribute to expanding the Job Demands-Resources model. While previous research [50] demonstrated that contagion of positive (i.e., joy) and negative emotions (i.e., anger) may serve respectively as a job resource and a job demand in predicting job burnout, our findings further expand this framework and qualifies contagion as a job resource/demand in developing/preventing stress related to economic adversities. Noteworthy, the viral spreading of anger (i.e., anger contagion) at work increased employees' affective reactions to economic adversities as well as their injuries rates and the tendency to under-report accidents.

\subsection{Practical implications}

From a practical perspective, the results of this study have important implications. Not only are the economic costs of workplace injuries high (e.g., lost wages and productivity, medical costs, and administrative expenses), but also not reporting an accident has negative consequences in that untreated injuries can worsen and cause even greater health and productivity problems over time $[12,73]$. Paradoxically, an additional negative consequence of under-reporting is that employees take on the financial responsibility of any medical claims that may result since they cannot access worker's compensation if they do not report the accident, thus potentially further eroding their financial situation.

Our findings also reveal that financial stress is a key mediator between emotional contagion and poor safety outcome. According to appraisal theory of emotion and stress [74], an environment that a person apprises as relevant and threatening constitutes a source of stress. Furthermore, as suggested by Probst [75], involvement practices and participative decision-making that allow employees to develop sense-making and regain control also help in experiencing fewer negative emotions regarding unstable situations. Given that individuals who believe to be able to protect themselves from negative events at work may be less vulnerable to the effects of economic stressors [9], intervention programs might fruitfully provide management and employees with tools to help them augment the experience of absorption of joy, and conversely inhibit the experience of absorbing other's anger. Effective emotion management requires knowledge about the nature of emotions Andrieş [76], thus enabling to improve employees' ability to manage their emotional resources so as to adapt to job requirements and work to increase organizational effectiveness and safety. Specifically, employees self-awareness of emotional processes is the first step to recognize how one's own social interactions with people at work contribute to feelings of joy and anger, as well as the mechanisms through which these emotions may cause one to experience high/low economic stress as well as injuries. Consistent with Gross's [77] model of emotional regulation, this may help incumbents to develop copying skills by examining the conditions under which they reappraise their cognitions and subsequently regulate their emotions.

\subsection{Study strengths, limitations, and future} directions

While the current findings are promising and suggest that employees' subjective concerns on their financial situation overlook employment related worries in predicting an increase in poor safety outcomes, they also warrant further investigation. Our study is an important first step at demonstrating the relationship between income-related economic stress and safety outcomes; yet, this framework can be further expanded. While we focused on employee affective reaction to their employment- and incomerelated situation, future research could consider the concurrent role of cognitive facets of employment(i.e., job insecurity) and income-related (i.e., financial inadequacy) economic stressors in predicting workplace injuries and accident under-reporting. Further, consistent with the global worries about the financial crisis $[3,5]$, future studies should investigate the potentially detrimental effects of emotional 
contagion of fear in boosting employees economic stress and subsequent workplace injuries as well as under-reporting behaviors. An additional venue for advancing the literature on the link between economic stress and job safety points at incorporating the study of how contextual effects of organizational processes in one's occupation, such as safety culture, safety climate, and job insecurity climate [31], influence and shape the individual experience of economic stress. Toward that end, future studies considering possible organizational differences and taking a multilevel modelling approach should target employees nested within a large number and wide variety of organizations. An additional notable strength of the current study is the two-country data, which increases the likelihood of generalizability of the research findings and applications. However, while the set of data in the US and Italian context was drawn from numerous organizational samples representing a wide variety of industry sectors, they were nonetheless convenience samples. Hence, our findings might arguably be affected by self-selection biases.

Finally, the current study relies on cross-sectional and self-report data. Although previous research indicates that self-reports of safety-related behavior are appropriate and "may be the best choice when time and monetary resources restrict measurement to one indicator" [62, p. 51], longitudinal studies could provide added support for the causal links posited in our model. Longitudinal research could also better delineate the cross-lagged associations between perceived income-related (i.e., financial stress) and employment-related (i.e., affective job insecurity) stressors, and safety outcomes in the wake of economic instability and employment uncertainty.

\section{Conflict of interest}

None to report.

\section{References}

[1] Grusky DB, Western B, Wimer C. The consequences of the great recession. In D.B. Grusky, B. Western, C. Wimer (Eds.), The great recession (pp. 3-20). New York, NY: Russell Sage Foundation, 2011.

[2] American Psychological Association Stress in America. Paying with our health 2015. Retrievable from: https://www.apa.org/news/press/releases/stress/2014/ stress-report.pdf
[3] Bloomberg MR. Shift: The Commission on Work, Workers, and Technology. Report of Findings 2017. Retrievable from: https://consumermediallc.files.wordpress.com/2017/05/ shift_report_final_5-16-17.pdf

[4] Eurostat. Key figures on Europe 2015. Retrieved from: http://ec.europa.eu/eurostat/documents/3217494/7072644/ KS-EI-15-001-EN-N.pdf/

[5] Eurobarometer. Flash Eurobarometer 398: Working conditions. Brussels: European Commission, 2014.

[6] Gelfand MJ, Aycan Z, Erez M, Leung K. Cross-Cultural Industrial Organizational Psychology and Organizational Behavior: A Hundred-Year Journey. Journal of Applied Psychology 2017. doi: 10.1037/apl0000186

[7] Schmidt S. Shall we really do it again? The powerful concept of replication is neglected in the social sciences, Review of General Psychology. 2009;13(2):90-100.

[8] Voydanoff P. Economic distress and family relations: A review of the eighties. Journal of Marriage and the Family. 1990;52(4):1099-115.

[9] Probst TM. Economic stressors. In J. Barling, K. Kelloway, \& M. Frone (Eds.) Handbook of work stress, (pp. 267-297). Thousand Oaks, CA: Sage Publication, Inc, $2005 \mathrm{a}$.

[10] Probst TM. Layoffs and tradeoffs: production, quality, and safety demands under the threat of job loss. Journal of Occupational Health Psychology. 2002;7(3):211.

[11] Probst TM. Safety and insecurity: exploring the moderating effect of organizational safety climate. Journal of Occupational Health Psychology. 2004;9(1):3.

[12] Probst TM, Barbaranelli C, Petitta L. The relationship between job insecurity and accident underreporting: A test in two countries. Work \& Stress. 2013;27:383-402.

[13] Probst TM, Petitta L, Barbaranelli C, Lavaysse LM. Moderating effects of contingent work on the relationship between job insecurity and employee safety. Safety Science. 2016: $1-9$.

[14] Sinclair RR, Cheung JH. Money matters: Recommendations for financial stress research in occupational health psychology. Stress and Health. 2016;32(3):181-93.

[15] Probst TM. Financial Insecurity: Putting our Money where our Mouth is. Stress and Health. 2016;32(3):179-80.

[16] Huang G, Lee C, Ashford S, Chen Z, Ren X. Affective job insecurity: A mediator of the cognitive job insecurity and employee outcomes relationships. International Studies of Management and Organizations. 2010;40:20-39.

[17] Probst TM. Development and validation of the Job Security Index and the Job Security Satisfaction Scale: A classical test theory and IRT approach. Journal of Occupational and Organizational Psychology. 2003a;76:451-67.

[18] Greenhalgh L, Rosenblatt Z. Job insecurity: Toward conceptual clarity. Academy of Management Review. 1984;9:438-48.

[19] Hatfield E, Cacioppo JT, Rapson RL. Emotional contagion. New York: Cambridge University Press, 1994.

[20] Barsade SG, Ramarajan L, Westen D. Implicit affect in organizations. Research in Organizational Behavior. 2009;29:135-62.

[21] Barsade S, Gibson D. Why does affect matter in organizations? Academy of Management Perspectives. 2007;21:36-59.

[22] Le Blanc PM, Bakker AB, Peeters MCW, van Heesch Nicolette CA, Schaufeli WB. Emotional job demands and burnout among oncology care providers. Anxiety, Stress \& Coping. 2001;4(3)243-63. doi:10.1080/ 10615800108248356 
[23] Sverke M, Hellgren J, Näswall K. No security: A metaanalysis and review of job insecurity and its consequences. Journal of Occupational Health Psychology. 2002;7:242-64.

[24] Brockner J, Grover S, Reed TF, Dewitt RL. Layoffs, job Insecurity, and survivors' work effort: Evidence of an inverted-U relationship. Academy of Management Journal. 1992;35(2):413-25. doi:10.2307/256380

[25] Størseth F. Changes at work and employee reactions: Organizational elements, job insecurity, and short-term stress as predictors for employee health and safety. Scandinavian Journal of Psychology. 2006;47(6):541-50.

[26] Probst TM, Brubaker TL. The effects of job insecurity on employee safety outcomes: cross-sectional and longitudinal explorations. Journal of Occupational Health Psychology. 2001;6(2):139.

[27] Quinlan M. The hidden epidemic of injuries and illness associated with the global expansion of precarious employment. In C. L. Peterson \& C. Mayhew (Eds.), Occupational Health and Safety: International Influences and the New Epidemics (pp. 53-74). Amityville, NY: Baywood Publishing, 2005.

[28] Borg I, Elizur D. Job insecurity: Correlates, moderators and measurement. International Journal of Manpower. 1992;13(2):13-26. doi:10.1108/01437729210010210

[29] Ashford S, Lee C, Bobko P. Content, causes, and consequences of job insecurity: A theory-based measure and substantive test. Academy of Management Journal. 1989;32:803-829.

[30] Jiang L, Lavaysse LM. Cognitive and affective job insecurity: A meta-analysis and a primary study. Journal of Management. 2018;44(6):2307-42.

[31] Jiang L, Probst TM. A multilevel examination of affective job insecurity climate on safety outcomes. Journal of Occupational Health Psychology. 2016;21(3):366-77.

[32] Jiang L, Probst TM. Organizational communication: A buffer in times of job insecurity? Economic and Industrial Democracy. 2016;35(3). Doi:10.1177/0143831X13489356

[33] Aldana SG, Liljenquist W. Validity and reliability of a financial stress survey. Financial Counseling and Planning. 1998;9(2):11-18.

[34] Marjanovic Z, et al. Evaluation of the Financial Threat Scale (FTS) in four European, non-student samples. Journal of Behavioral and Experimental Economics. 2015;55:72-80.

[35] Starrin B, Åslund C, Nilsson KW. Financial stress, shaming experiences, and psychosocial ill-health: Studies into the finances-shame model. Social Indicators Research. 2009;91:283-98.

[36] Brett JF, Cron WL, Slocum JW. Economic dependency on work: A moderator of the relationship between organizational commitment and performance. The Academy of Management Journal. 1995;38:261-71.

[37] Clark A, Knabe A, Rätzel S. Boon or bane? Others' unemployment, well-being and job insecurity. Labour Economics. 2010;17:52-61.

[38] Låstad L. Job insecurity climate: The nature of the construct, its associations with outcomes, and its relation to individual job insecurity (Doctoral dissertation, Stockholm University, 2015).

[39] Hatfield E, Cacioppo JT, Rapson RL. Emotional contagion. Current Directions in Psychological Science. 1993;2(3):969. doi:10.1111/1467-8721.ep10770953

[40] Hatfield E, Rapson RL. Emotional contagion and the communication of emotions. In M. T. Palmer \& G. A. Barnett (Ed.). Progress in communication sciences (1998). (Vol. 14, pp. 73-89). Stamford, CT: Ablex.
[41] Iacoboni M. Imitation, empathy, and mirror neurons. Annual Review of Psychology. 2009;60(1):653-70. doi:10.1146/annurev.psych.60.110707.163604

[42] Rizzolatti G, Sinigaglia C. Mirrors in the brain: How our minds share actions and emotions. New York: Oxford University Press Inc. 2008.

[43] LeDoux J. Synaptic self: How our brains become who we are, Viking, NY, 2002.

[44] Hatfield E, Forbes M, Rapson RL. Marketing love and sex. Society. 2012;49(6):506-11. doi:10.1007/s12115-0129593-1

[45] Petitta L, Naughton S. Mapping the association of emotional contagion to leaders, colleagues, and clients: Implications for leadership. Organization Management Journal. 2015;12(3):178-92. doi:10.1080/15416518.2015.1073577

[46] Bakker AB. Flow among music teachers and their students The crossover of peak experiences. Journal of Vocational Behavior. 2005;66:26-44.

[47] Doherty RW. The Emotional Contagion Scale: A measure of individual differences. Journal of Nonverbal Behavior. 1997;21:131-154. doi:10.1023/A:1024956003661

[48] Ekman P. Basic emotions. In Dalgleish T, Power T (Eds.). The handbook of cognition and emotion (pp. 45-60). Sussex, UK: John Wiley \& Sons, Ltd. 1999.

[49] Demerouti E, Bakker AB, Nachreiner F, Schaufeli WB. The job demands-resources model of burnout. Journal of Applied Psychology. 2001;86(3):499-512.

[50] Petitta L, Jiang L, Härtel CEJ. Emotional Contagion and Burnout Among Nurses and Doctors: Do Joy and Anger from Different Sources of Stakeholders Matter? Stress \& Health. 2016:1-12. DOI:10.1002/smi.2724

[51] Sundin L, Hochwälder J, Lisspers JA. Longitudinal examination of generic and occupational specific job demands, and work-related social support associated with burnout among nurses in Sweden. Work. 2011;38(4):389-400.

[52] de Jonge J, Dormann C. The DISC Model: Demand-Induced Strain Compensation mechanisms in job stress. In Dollard, MF, Winefield, HR, Winefield AH. (eds.), Occupational stress in the service professions (pp. 43-74). London: Taylor \& Francis, 2003.

[53] Van den Tooren M, de Jonge J, Dorman C. The demandinduced strain compensation model: Background, key principles, theoretical underpinnings, and extended empirical evidence. In Caetano A, Silva S, Chambel MJ. (Eds.), New challenges and interventions in the psychosocial work environment. Munich: Rainer Hampp. 2011.

[54] Petitta L, Jiang L. How emotional contagion relates to burnout: A moderated mediation model of job insecurity and group member prototypicality. International Journal of Stress Management. 2020;27(1):12-22. https://doi.org/10.1037/str0000134.

[55] Petitta L, Probst TM, Ghezzi V, Barbaranelli C. Cognitive failures in response to emotional contagion: Their effects on workplace accidents. Accident Analysis and Prevention. 2019;125:165-73. https://doi.org/10.1016/j.aap.2019.01.018.

[56] Gilboa S, Shirom A, Fried Y, Cooper CL. A meta-analysis of work demand stressors and job performance: examining main and moderating effects. Personnel Psychology. 2008;61(2):227-71.

[57] Dunbar E. The role of psychological stress and prior experience in the use of personal protective equipment. Journal of Safety Research. 1993;24:181-7.

[58] Shoss MK, Probst TM. Multilevel outcomes of economic stress: An agenda for future research. In Perrewé PL. 
Halbesleben JRB. Rosen CC. (Eds.), The role of the economic crisis on occupational stress and well-being: Research in occupational stress and well-being (Vol. 10, pp. 43-86). Emerald Group Publishing Limited, 2012.

[59] Durand A-C, Bompard C, Sportiello J, Michelet P, Gentile S. Stress and burnout among professionals working in the emergency department in a French university hospital: Prevalence and associated factors. Work. 2019;63(1):57-67.

[60] De Cuyper N, Baillien E, De Witte H. Job insecurity and workplace bullying among targets and perpetrators: moderation by employability. Work \& Stress. 2009;23:206-24. doi:10.1080/02678370903257578

[61] Probst TM, Graso M, Estrada AX, Greer S. Consideration of future safety consequences: A new predictor of employee safety. Accident Analysis \& Prevention. 2013;55:124-34.

[62] Lusk S, Ronis D, Baer L. A comparison of multiple indicators: Observations, supervisor report, and self-report measures of worker's hearing protection use. Evaluation and the Health Professions. 1995;18(1):51-63.

[63] Hanisch K. The Job Descriptive Index revisited: Questions about the question mark. Journal of Applied Psychology. 1992; 7:377-82.

[64] Prawitz AD, Garman ET, Sorhaindo B, O’Neill B, Kim J, Drentea P. In Charge financial distress/financial well-being scale: Development, administration, and score interpretation. Financial Counseling and Planning. 2006;17(1):34-50.

[65] Muthén LK, Muthén BO. Mplus User's Guide. Eighth Edition. Los Angeles, CA: Muthén \& Muthén, 1998-2017.

[66] Beauducel A, Herzberg PY. On the performance of maximum likelihood versus means and variance adjusted weighted least squares estimation in CFA. Structural Equation Modeling. 2006;3(2):186-203.

[67] Kline RB. Principles and practice of structural equation modeling (3nd edition). New York: Guilford. 2011.
[68] Cheung GW, Rensvold RB. Evaluating goodness-of-fit indexes for testing measurement invariance. Structural Equation Modeling: A Multidisciplinary Journal. 2002;9(2):233-55. doi:10.1207/S15328007SEM0902_5

[69] MacKinnon DP. Introduction to Statistical Mediation Analysis. Mahwah, NJ: Erlbaum. 2008.

[70] Bureau of Labor Statistics. Employer-reported workplace injury and illness summary 2018. Available from https://www.bls.gov/iif/.

[71] Italian National Workers Compensation Authority[Istituto Nazionale per l'Assicurazione contro gli Infortuni sul Lavoro- INAIL] 2019. Analisi biennale del numero di incidenti [Biannual analysis of the number of accidents]. Available at https://www.inail.it/cs/internet/docs/alg-datiinail-2019-ottobre.pdf.

[72] Warr PB. Work, unemployment, and mental health. Oxford, UK: Clarendon Press, 1987.

[73] Gallagher RM, Myers P. Referral delay in back pain patients on worker's compensation: Costs and policy implications. Psychosomatics. 1996;37:270-84.

[74] Lazarus RS, Folkman S. Stress, appraisal, and coping. New York, NY: Springer. 1984.

[75] Probst TM. Participative decision making: A simple solution to job insecurity's consequences? Paper presented at the 3rd biennial APA/NIOSH Conference on Work, Stress, and Health, Toronto, Canada, 2003b, March.

[76] Andrieş AM. Positive And Negative Emotions Within The Organizational Context. Global Journal of Human Social Science. 2011;11(9):26-39.

[77] Gross JJ. The emerging field of emotion regulation: An integrative review. Review of General Psychology. 1998;2:271-299. 